Supplement of Hydrol. Earth Syst. Sci., 25, 2373-2386, 2021

https://doi.org/10.5194/hess-25-2373-2021-supplement

(c) Author(s) 2021. CC BY 4.0 License.

(c) (i)

Supplement of

\title{
A simple cloud-filling approach for remote sensing water cover assessments
}

\section{Connor Mullen et al.}

Correspondence to: Marc F. Müller (mmuller1@ nd.edu)

The copyright of individual parts of the supplement might differ from the article licence. 


\section{S1 Acquisition and bias correction of in situ lake extent data}

Daily-averaged water extents were obtained from the United States Geological Survey (2 reservoirs in Upstate New York) and Texas Water Development Board (4 reservoirs in Texas) and bias-corrected to match the water extent obtained from Landsat imagery on clear days. The source of this bias is unclear (and beyond the scope of this paper) but might be related to temporal

5 changes in the elevation-area-capacity curves, for instance due to sedimentation processes (Raje and Mujumdar, 2010). An additive bias was assumed and corrected as follows:

$$
A_{i}^{*}=A_{i}-\overline{A_{i}}+\overline{A_{i}^{(R S)}}
$$

where $A_{i}$ indicates a (biased) in situ area estimate, $\overline{A_{i}}$ its average value across observations, and $\overline{A_{i}^{(R S)}}$ indicates the average lake area from the remote sensing observation. 


\section{References}

Raje, D. and Mujumdar, P.: Reservoir performance under uncertainty in hydrologic impacts of climate change, Advances in Water Resources, $33,312-326,2010$. 

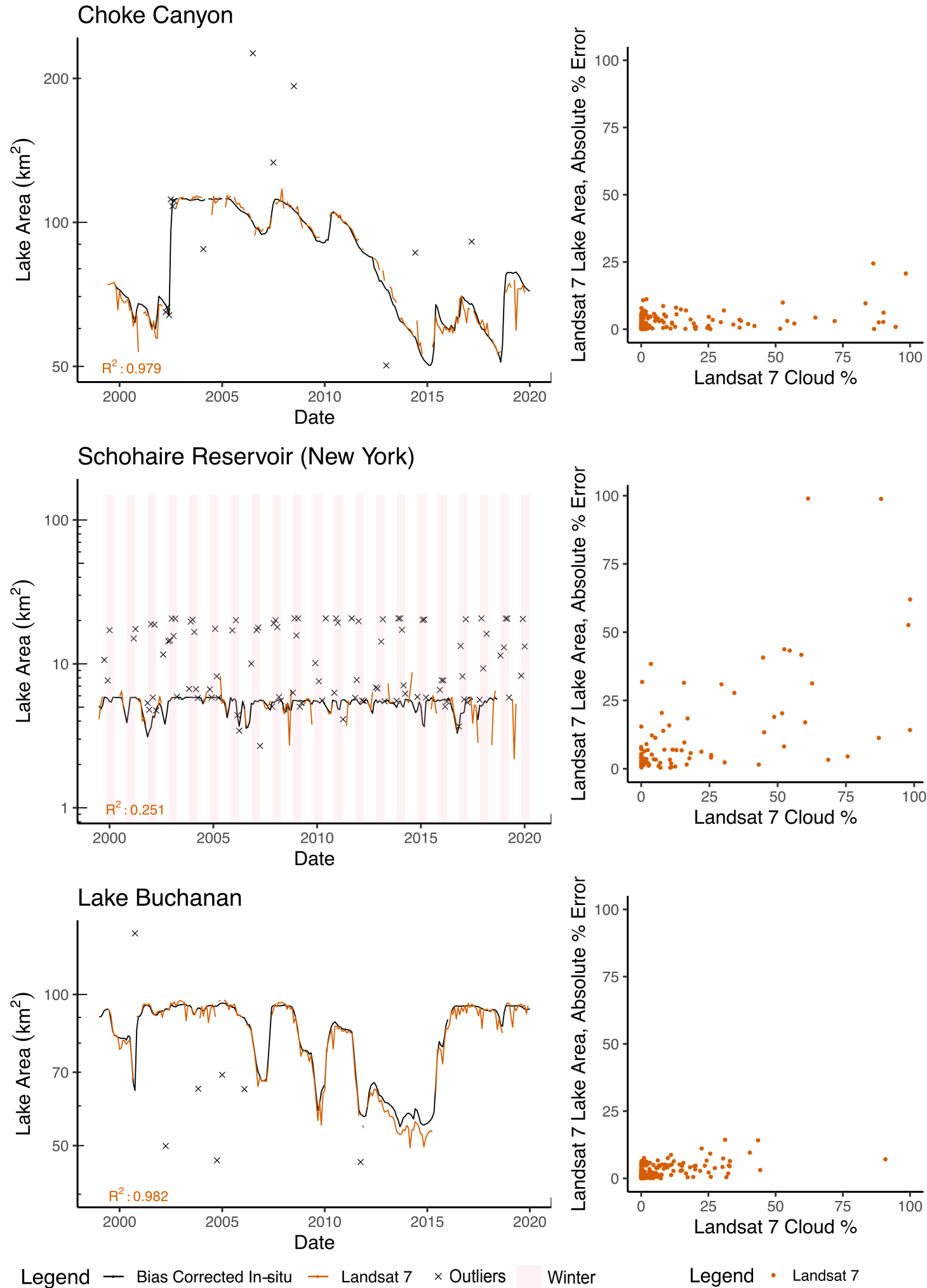

Figure S 1. Application to lakes with in situ observation data Left: Tظ̈me series representation water extent from in situ observation (black) and Landsat 7 (brown). Automatically removed outliers (crosses) are also displayed for indicative purpose. Winter months (December to February) are shaded out for Schohaire Reservoir NY. Left Scatter-plot of absolute percentage errors on Landsat 7 water extent estimates (compared to in situ observations) against the proportion of the lake's maximum footprint that is covered by clouds. 